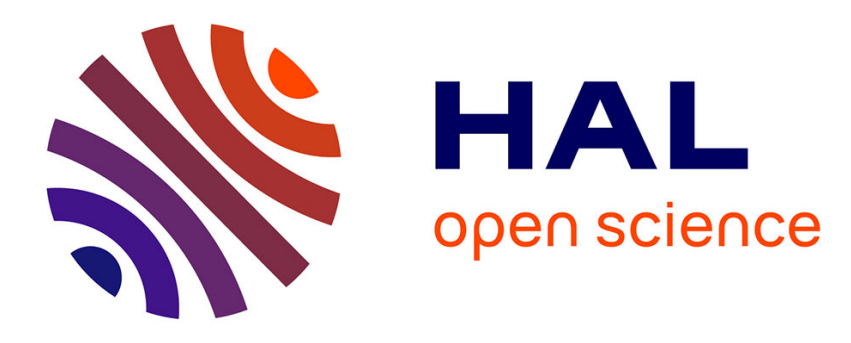

\title{
Transformation Reversibility in Fe-Mn-Si Shape Memory Alloy
}

K. Tsuzaki, Y. Natsume, T. Maki

\section{To cite this version:}

K. Tsuzaki, Y. Natsume, T. Maki. Transformation Reversibility in Fe-Mn-Si Shape Memory Alloy. Journal de Physique IV Proceedings, 1995, 05 (C8), pp.C8-409-C8-414. 10.1051/jp4:1995861 . jpa00254110

\section{HAL Id: jpa-00254110 https://hal.science/jpa-00254110}

Submitted on 1 Jan 1995

HAL is a multi-disciplinary open access archive for the deposit and dissemination of scientific research documents, whether they are published or not. The documents may come from teaching and research institutions in France or abroad, or from public or private research centers.
L'archive ouverte pluridisciplinaire HAL, est destinée au dépôt et à la diffusion de documents scientifiques de niveau recherche, publiés ou non, émanant des établissements d'enseignement et de recherche français ou étrangers, des laboratoires publics ou privés. 


\title{
Transformation Reversibility in Fe-Mn-Si Shape Memory Alloy
}

\author{
K. Tsuzaki, Y. Natsume and T. Maki \\ Department of Materials Science and Engineering, Kyoto University, Yoshida-honmachi, Sakyo-ku, \\ Kyoto 606-01, Japan
}

\begin{abstract}
The change of the surface relief associated with stress-induced epsilon martensite before and after the reverse transformation in an $\mathrm{Fe}-33 \% \mathrm{Mn}-6 \% \mathrm{Si}$ alloy $(\mathrm{Ms}=264 \mathrm{~K})$ has been investigated. The permanent strain of a $2.7 \%$ tensile-strained specimen was $1.1 \%$ after the reverse transformation. In this specimen, a large part of surface relief still remained after heating to $623 \mathrm{~K}$ (above Af). When five training cycles of $2.5 \%$ straining at room temperature and heating at $623 \mathrm{~K}$ were applied, the permanent strain became negligible and the surface relief vanished well. TEM observations showed that usual permanent slip deformation hardly occurred in the interior of an austenite grain in a 3.8\% tensile-strained specimen where the permanent strain after the reversion was $2 \%$. These results indicate that the permanent strain in the shape memory behavior is mainly attributed to the lack of transformation reversibility, i.e., the lack of reversible movement of Shockley partial dislocations. The conditions for the reversibility were discussed and the importance of the back stress formed by the forward transformation was pointed out. The effects of traning were also briefly discussed.
\end{abstract}

\section{INTRODUCTION}

Fe-high $\mathrm{Mn}-\mathrm{Si}$ alloys, which undergo $\gamma(\mathrm{fcc})$ to $\varepsilon$ (hcp) martensitic transformation, exhibit a pronounced shape memory effect [1-3]. The origin of shape memory effect of these alloys is the reversion of stress-induced $\varepsilon$ martensite $[3,4]$. A shape change must hence be accomplished by stressinduced martensitic transformation without permanent slip in austenite $(\gamma)$ in order to obtain a good shape memory effect. Moreover, the reverse transformation must take place by the backward movement of the Shockley partial dislocations having operated in the forward transformation. The permanent strain remaining after the reverse transformation is thus attributed to two factors: (1) the occurrence of permanent slip during a shape change and (2) the lack of transformation reversibility, i.e., the lack of reversible movement of partial dislocations. However, it is still unclear how much fraction of the permanent strain results from each factor.

In the present study, the lack of transformation reversibility has been investigated by observing the surface relief related to stress-induced martensite before and after the reverse transformation to understand the causes of permanent strain in the shape memory behavior of $\mathrm{Fe}-\mathrm{Mn}-\mathrm{Si}$ alloys.

\section{EXPERIMENTAL}

An Fe-33Mn-6Si alloy, a conventional Fe-Mn-Si alloy exhibiting a good shape memory effect, was prepared by induction melting in an argon gas atmosphere. The chemical composition of the alloy was $0.0015 \% \mathrm{C}, 6.19 \% \mathrm{Si}, 32.7 \% \mathrm{Mn}, 0.001 \% \mathrm{P}, 0.007 \% \mathrm{~S}$, and balance $\mathrm{Fe}$ (mass\%). After hot-rolling and solution treatment at $1323 \mathrm{~K}$ in air, the surface layer of a plate with $11 \mathrm{~mm}$ in thickness was removed by $0.5 \mathrm{~mm}$. The plate was austenitized at $1273 \mathrm{k}$ for $3.6 \mathrm{ks}$ in argon and then spark-machined into tensile test specimens with a parallel portion of $50 \mathrm{~mm}$ in length, $10 \mathrm{~mm}$ in width and $1 \mathrm{~mm}$ in thickness. After slightly polishing the surface layers, the specimens were finally annealed at $1273 \mathrm{~K}$ for $600 \mathrm{~s}$ in argon to eliminate the influences of machining. The martensitic transformation start temperature (Ms) was determined to be $264 \mathrm{~K}$ by means of dilatometry. 
Tensile deformation was conducted at room temperature $(296 \pm 2 \mathrm{~K})$ on an Instron type machine with a cross head speed of $1 \mathrm{~mm} / \mathrm{min}$. The specimens were deformed by various amounts of strain and then unloaded. These specimens were subsequently heated up to $873 \mathrm{~K}$ (above Af, the finish temperature of the reversion of stress-induced martensite). The degree of shape recovery (DSR) was determined from the change in the gage length of a specimen using an equation of $\mathrm{DSR}(\%)=(\mathrm{L} 1-\mathrm{L} 2) /(\mathrm{L} 1-\mathrm{L} 0) \times 100$, where $\mathrm{L} 0, \mathrm{~L} 1$ and $\mathrm{L} 2$ are the gage length before and after the tensile deformation and after the reverse transformation, respectively.

For observations of surface relief change, some tensile specimens were electrolytically polished to get a fine surface before tensile deformation. In order to keep the surface from contamination, these specimens were encapsulated after tensile deformation and heated at $623 \mathrm{~K}$ which is lower than the heating temperature (873K) used for the DSR measurements described above. It had been confirmed that $623 \mathrm{~K}$ is still higher than Af and the DSR is not affected by this difference of heating temperature. Surface relief observations were performed before and after the reverse transformation in the identical regions by means of a Nomarsky-type optical microscope.

\section{RESULTS}

Figure 1 shows the degree of shape recovery as a function of tensile strain. The changes of recoverable strain and permanent strain are depicted in Fig. 2. The permanent strain increases monotonously with tensile strain. On the other hand, the recoverable strain saturate at around 5\% tensile strain and slightly decreases when the tensile strain becomes larger than $10 \%$. It is noteworthy that the amount of stressinduced martensite itself continuously increases with tensile deformation up to 0.35 true strain, at which the volume fraction of martensite reaches 0.5 [5]. The saturation and/or decrease of recoverable strain thus indicates that some stress-induced martensite plates cannot recover their original shape after the reversion in the cases of larger tensile strain than $10 \%$.

It should be noted in Figs. 1 and 2 that the alloy did not exhibit a complete shape memory effect even when the tensile strain was as small as $0.7 \%$, at which $0.1 \%$ strain was observed as the permanent strain. The change in surface relief of the $0.7 \%$ tensile-strained specimen is shown in Fig. 3. Surface relief still remains after the reversion treatment [Fig.3(b)]. This result emphasizes that the lack of the transformation reversibility causes the permanent strain even in the case of small tensile strain. Among the martensite plates with the same habit plane in an austenite grain some plates maintain the reversibility but the other plates do not, indicating that the transformation reversibility is different among the martensite plates. Moreover, in the martensite plates intersecting each other [indicated by the arrow in Fig. 3(a)] their surface relief is not seen after the reversion. This result indicates that the intersection of martensite plates does not necessarily hinder the reversible movement of Shockley partial dislocations. Figure 4 is micrographs of a relatively large region in the $0.7 \%$ tensile-strained specimen, showing that the remaining of surface relief is not special behavior that is observed in a particular austenite grain. The degree of surface relief vanishment is however different among grains: surface relief is hardly observed in a grain marked $\mathrm{A}$ after the reversion [Fig.4(b)].

Figure 5 shows the change of surface relief in a $2.7 \%$ tensile-strained specimen where the permanent strain was $1.1 \%$ and residual surface relief was observed in all austenite grains after the reversion treatment. The ability of shape recovery is different among martensite plates like the case of the $0.7 \%$ tensile-strained specimen (Fig. 3). For instance, the surface relief of plate 1 vanishes well, the relief of plate 2 somewhat changes, and the relief of plate 3 remains unchanged. In general, thin martensite plates tend to recover well their original shape and thicker plates have less ability of shape recovery. By comparing Fig. 5(b) with Fig. 3(b), the martensite plates retaining surface relief after the reversion are found to be much more in Fig. 5(b) where the permanent strain was 1.1\%. It must be noted that after polishing and etching no martensite plates were observed in the specimen after the reversion treatment of $623 \mathrm{~K} 0.6 \mathrm{ks}$ and hence the reverse transformation had been surely completed in Fig. $5(\mathrm{~b})$. It is thus likely that the increase in the permanent strain with tensile strain is caused by the increase of the martensite plates without the ability of shape recovery.

If the change in surface relief observed in the present study certainly represents the transformation reversibility, all of the surface relief must disappear in a specimen exhibiting a complete shape memory 


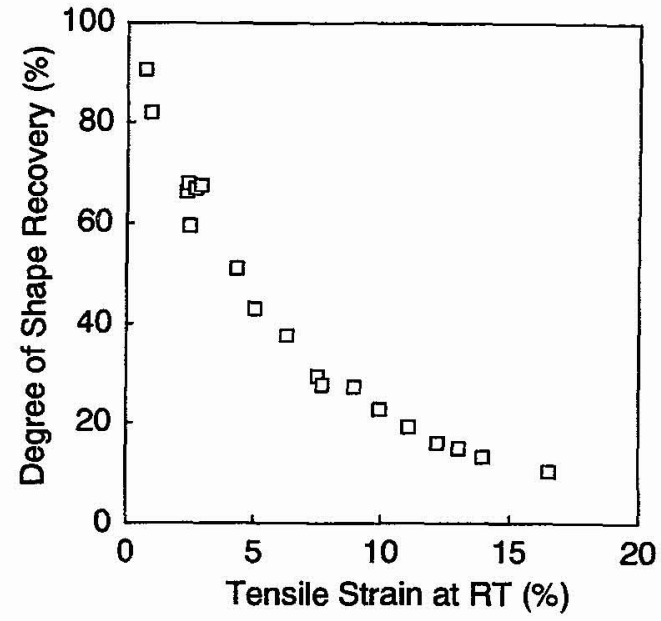

Figure 1: Degree of shape recovery as a function of tensile strain in the Fe-33Mn-6Si alloy.
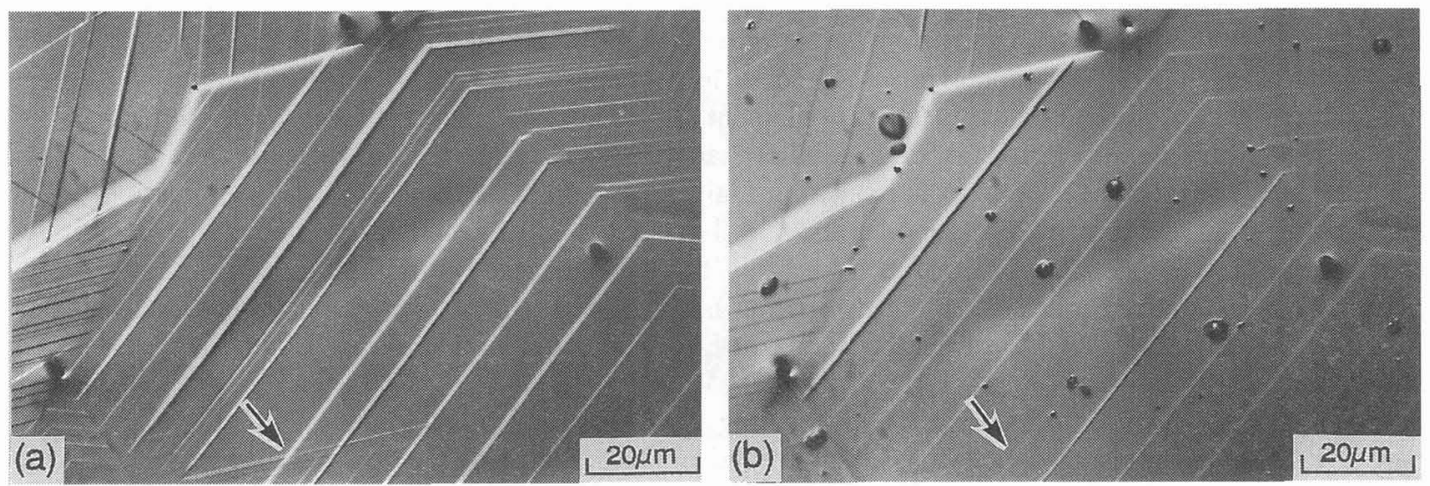

Figure 3: Change in surface relief of the $0.7 \%$ tensile-strained specimen. Fe-33Mn-6Si.

(a) before the reversion treatment, (b) after the revesion treatment.
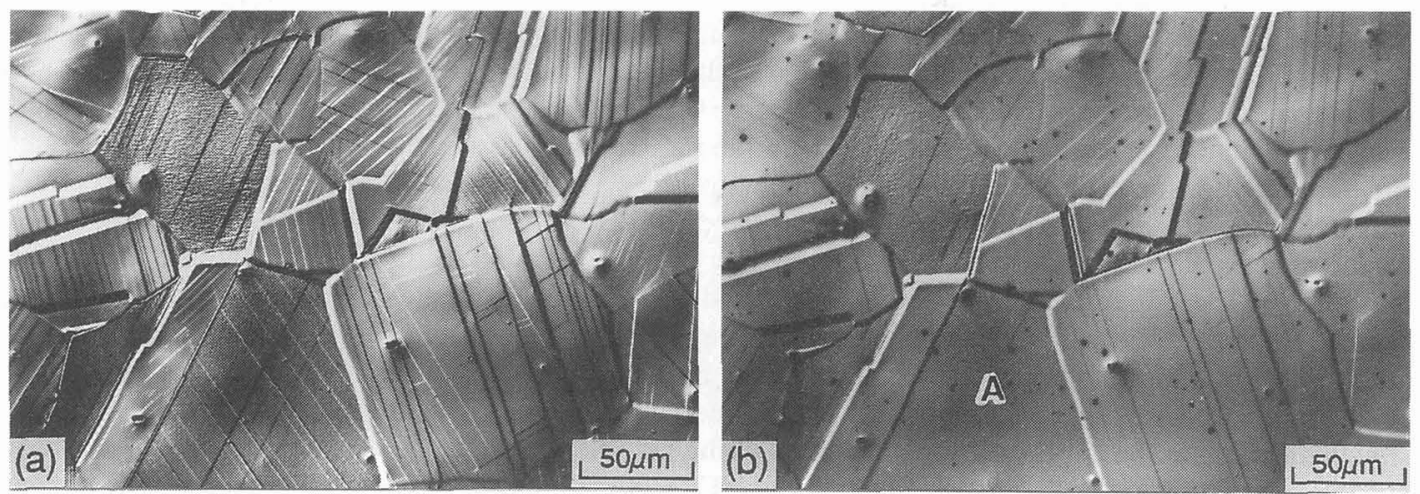

Figure 4: Change in surface relief of the 0.7\% tensile-strained specimen. Fe-33Mn-6Si. Low mag. of Fig.3.

(a) before the reversion treatment, (b) after the revesion treatment. 
effect. To get such a specimen, so-called training treatment was performed. The training treatment consisted of $2.5 \%$ tensile deformation and $873 \mathrm{~K}$ annealing. After five training cycles, the specimen was electrolytically polished for surface relief observation. The change of surface relief in the sixth cycle is shown in Fig. 6. After heating at $623 \mathrm{~K}$, this specimen showed an almost complete shape memory effect (permanent strain; $0.1 \%$, recoverable strain; $2.4 \%$ and the degree of shape recovery; $96 \%$ ) and the surface relief well disappeared. Although very narrow striations are seen in Fig. 6(b), the vanishment of surface relief is evident compared with Fig. 5(b) where the permanent strain was $1.1 \%$ and the degree of shape recovery was $59 \%$. This result confirms that the residual surface relief after the reversion observed in the present study represents the lack of transformation reversibility.

\section{DISCUSSION}

Permanent strain in the shape memory behavior in Fe-Mn-Si alloys is attributed to both the occurrence of permanent slip deformation and the lack of transformation reversibility. An extreme case is that all of the martensite plates formed has the ability of shape recovery and the permanent strain results only from permanent slip deformation during a shape change. The present study has clearly denied this extreme case. The lack of transformation reversibility represented by residual surface relief has been observed irrespective of the amount of shape change. How much amount of permanent slip deformation had occurred in the present alloy is to be discussed next.

In the tensile deformation at room temperature, the $0.2 \%$ proof stress was $232 \mathrm{MPa}$ and the $2.5 \%$ flow stress was $337 \mathrm{MPa}$. We have recently reported that the $0.2 \%$ proof stress for usual slip deformation of the present alloy can be estimated to be $274 \mathrm{MPa}$ by extrapolating the $0.2 \%$ proof stresses at elevated temperatures [6]. Thus, permanent slip may occur in some extent in a $2.5 \%$ tensile-strained specimen. It was however found by TEM study that permanent slip deformation hardly takes place in the interior region of a grain when the tensile strain is smaller than $4 \%$. Figure 7 is a TEM micrograph taken from a $3.8 \%$ tensile-strained specimen. Some stacking faults which do not extend well are seen, as indicated by the arrow. These narrow stacking faults may be the traces of usual slip. However, the narrow stacking faults were not often observed, indicating that the tensile deformation had dominantly taken place by stress-induced martensitic transformation in this specimen. It can be thus concluded that the lack of transformation reversibility is the main cause for the permanent strain, at least when the tensile strain is smaller than $4 \%$.

In the $\varepsilon$ to $\gamma$ reverse transformation on heating without stress, three kinds of $a / 6<112>$ Shockley partial dislocations are equivalently possible to move on a (0001) $\varepsilon$ plane for obtaining the fcc phase with the same orientation as the matrix. If the reversion of a martensite plate takes place by the operation of these three kinds of partial dislocations with the same amount, its surface relief is essentially unchanged after the reversion. The surface relief can disappear only when the reverse transformation occurs by the backward movement of the Shockley partial dislocations having operated in the forward transformation. We must thus discuss the conditions for the reversible movement of partial dislocations to understand the lack of transformation reversibility observed in the present study.

Sade et al. [7] implied the existence of short range ordered structures or small coherent ordered particles related to $\mathrm{Si}$ in the austenite matrix for the transformation reversibility. This idea can account for the fact that the addition of Si to Fe-high Mn binary alloys improves the shape memory effect, although ordered structures or ordered particles have not yet been reported in $\mathrm{Fe}-\mathrm{Mn}-\mathrm{Si}$ alloys. It has been emphasized in the present study that the ability of shape recovery is different among the martensite plates formed in a given austenite grain (Figs. 3 and 5). Moreover, the transformation reversibility has become good by applying the training treatment (Fig. 6). It is likely that short range ordered structures are uniform within a grain and not changed by the training treatment. Thus, the present results cannot be interpreted based on the idea of short range ordered structures. This means that short range order structures must assist the transformation reversibility if they exist, but the existence of those is not enough to satisfy the transformation reversibility. There should be additional factors responsible for the transformation reversibility.

We have proposed $[8,9]$ that the reversible movement of partial dislocations is assisted by the back stress formed by the forward martensitic transformation. When accommodation deformation takes place 

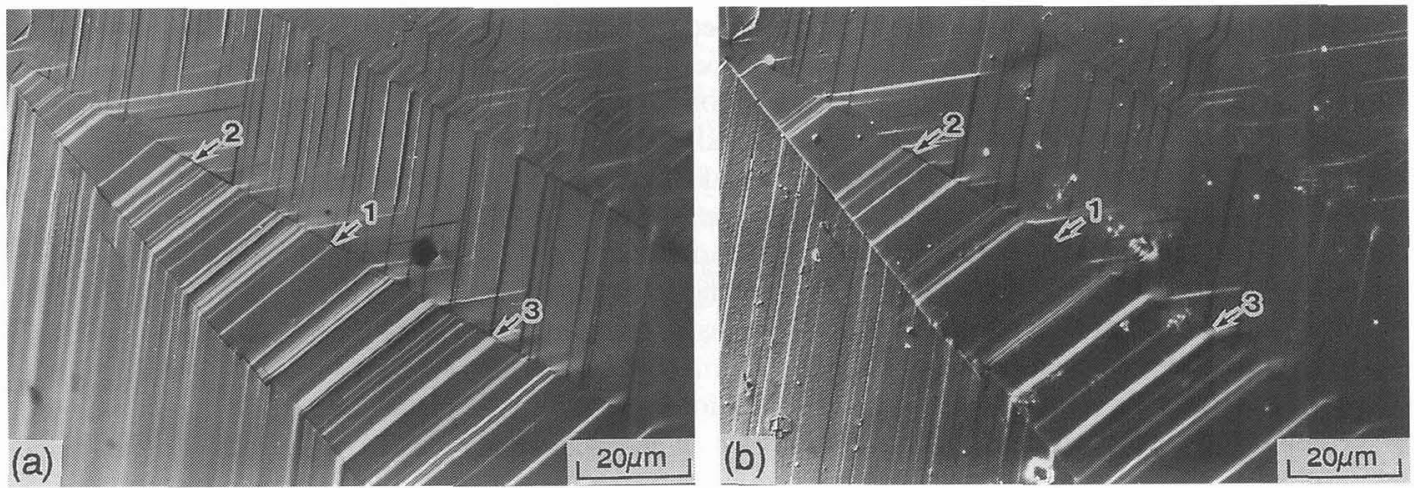

Figure 5: Change in surface relief of the $2.7 \%$ tensile-strained specimen. Fe-33Mn-6Si.

(a) before the reversion treatment, (b) after the revesion treatment.

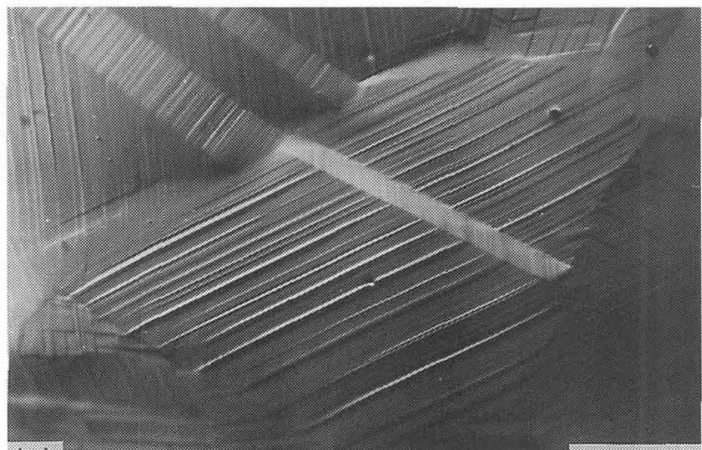

(a)

Figure 6: Change in surface relief of the $2.5 \%$ tensile-strained specimen after 5 training cycles. Fe-33Mn-6Si. (a) before the reversion treatment, (b) after the revesion treatment.

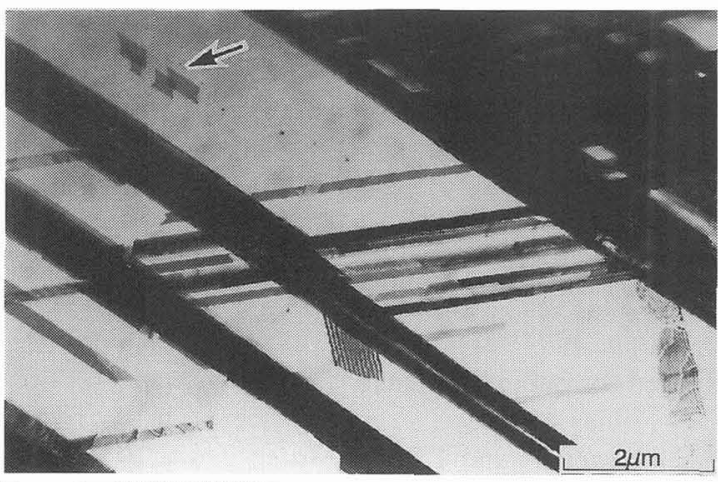

Figure 7: TEM microstructure in the interior region of an austenite grain of the $3.8 \%$ tensile-strained specimen. Fe$33 \mathrm{Mn}-6 \mathrm{Si}$. The arrow indicates narrow staking faults.

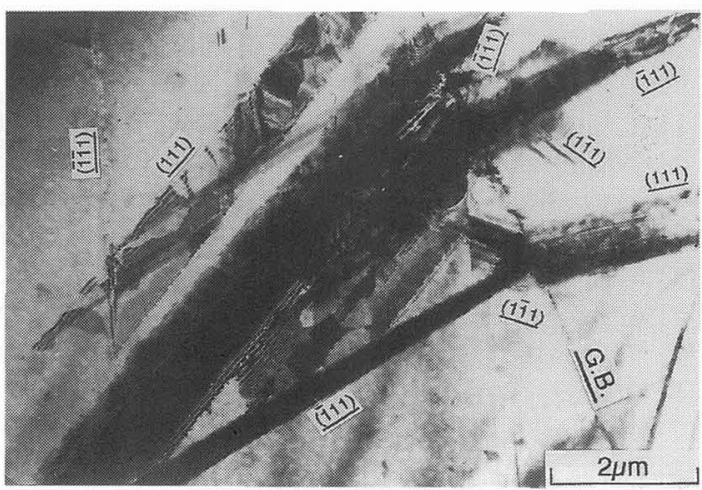

Figure 8: Inhomogeneous deformation structure near an austenite grain boundary (G.B.) in the $0.9 \%$ tensilestrained specimen. TEM micrograph. $\mathrm{Fe}-33 \mathrm{Mn}-6 \mathrm{Si}$. 
in the $\gamma$ around a tip of the $\varepsilon$ plate, the back stress decreases and hence the reversible movement becomes poor. This accommodation deformation would be performed by the occurrence of usual slip or the formation of other martensite variants. Such deformation was observed in the region near austenite boundaries even when the tensile strain was small. Figure 8 shows an example of inhomogeneous deformation observed in a $0.9 \%$ tensile-strained specimen. It was found by optical and TEM microscopy that one variant of martensite plates dominantly form in the interior region of a grain in this specimen. However, it is seen in Fig. 8 that deformation has taken place on all four $\{111\}$ planes in adjoining grains near the boundary. Narrow stacking faults, the traces of usual slip, are also seen in Fig. 8. This kind of inhomogeneous deformation decreases the internal stress for backward movement of the Shockley partial dislocations having operated to form the dominant martensite variant. The occurrence of accommodation deformation would be different for each martensite plate. In fact, no accommodation deformation was observed in grain boundary regions where martensite plates were relatively thin. Since the internal stress at the tips of martensite plates increases as the thickness of martensite plates increases, accommodation deformation occurs more readily near the tips of thicker martensite plates. This is in good agreement with the fact that thicker plates have less ability of shape recovery (Fig.5). We conclude that the back stress in addition to the short range order is important for the achievement of transformation reversibility.

In order to suppress the accommodation deformation in grain boundary regions, the stress-induced martensitic transformation should occur homogeneously in a grain and in a specimen. That is, the formation of a number of thin martensite plates would be desirable. It is noteworthy that in the trained sample [Fig. 6(a)] the martensite plates are uniform in size and distribution and no thick martensite plates are observed unlike the case without the training [Fig.5(a)]. The uniform deformation with a dominant martensite variant is evident even near austenite boundaries in Fig.6(a). It is thus very likely that the role of training treatment is to suppress the occurrence of inhomogeneous accommodation deformation by obtaining the uniform formation of thin martensite plates.

\section{CONCLUSIONS}

The permanent strain in the shape memory behavior of an $\mathrm{Fe}-33 \% \mathrm{Mn}-6 \% \mathrm{Si}$ alloy is mainly attributed to the lack of transformation reversibility, at least when tensile strain is smaller than $4 \%$. Thicker martensite plates have less ability of shape recovery. The back stress formed by stress-induced martensite is important for satisfying the transformation reversibility.

Acknowledgments: The authors are grateful for valuable discussions with Prof. Y. Tomota (Ibaraki University) and Dr. T. Furuhara (Kyoto University).

\section{References}

[1] A.Sato, Y.Yamaji and T.Mori, Acta Metall., 34 (1986) 287-294.

[2] M.Murakami, H.Otsuka, H.G.Suzuki and S.Matsuda, "Complete Shape Memory Effect in Polycrystalline Fe-Mn-Si Alloys", Proc. of Int. Conf. on Martens. Transf. (ICOMAT-86), Nara, Japan., I. Tamura Ed., (Jpn. Inst. Met., Sendai, 1987) pp.985-990.

[3] A.Sato and T.Mori, Mater. Sci. and Eng. A, 146 (1991) 197-204.

[4] A.Sato, E.Chishima, K.Soma and T.Mori, Acta metall., 30 (1982) 1177-1183.

[5] Y.Tomota, S.Ryufuku and M.Piao, J. Soc. Mater. Sci. Jpn, 40 (1991) 27-33.

[6] K.Tsuzaki, Y.Natsume, Y.Tomota and T.Maki, accepted for publication in Scr. metall. mater.,

[7] M.Sade, K.Halter and E.Hornbogen, Z.Metallkde., 79 (1988) 487-491.

[8] K.Tsuzaki, M.Ikegami, Y.Tomota, Y.Kurokawa, W.Nakagawara and T.Maki, Mater. Trans. JIM, 33 (1992) 263-270.

[9] T.Maki and K.Tsuzaki, "Transformation behavior of $\varepsilon$ Martensite in Fe-Mn-Si Shape Memory Alloys", Proc. of Inter. Conf. on Martensitic Transformations (ICOMAT-92), Monterey, Cal., 1992, C.M.Wayman and J.Parkins Eds., (Monterey Inst. for Adv. Studies, Monterey, 1993) pp.1151-1162. 